\title{
Free amino acid content in breast milk of adolescent and adult mothers in Ecuador
}

\author{
Manuel E Baldeón ${ }^{1}$, Julie A Mennella ${ }^{2 *}$, Nancy Flores ${ }^{3}$, Marco Fornasini ${ }^{1}$ and Ana San Gabriel ${ }^{4}$
}

\begin{abstract}
Because of increased incidence of teenage births and high prevalence of lactation in Latin America, we determined the patterning of free amino acids (FAAs) in breast milk of 65 primiparous Ecuadorian women of varying ages (14-27 years). An automatic amino acid analyzer quantified levels of FAAs in milk samples obtained at three lactation stages: colostrum, transition, and mature milk. Regardless of mother's age, most FAAs increased with time postpartum, with taurine, glutamic acid, glutamine, and alanine being most abundant in all stages.
\end{abstract}

Keywords: Human milk; Free amino acids; Glutamine; Glutamate; Lactation

\section{Introduction}

Exclusive breastfeeding for the first six months of life optimizes infant growth, development, and health and is beneficial to maternal health. Breast milk contains adequate nutrients, minerals, vitamins, and water for growing, but for reasons not completely understood, the mammary tissue of most mammals produces large amounts of nonprotein nitrogenous compounds, including free (protein-unbound) amino acids (FAAs) (Armstrong and Yates 1963; Svanberg et al. 1977; Lei et al. 2012).

Albeit limited, most research to date quantifying sources of nonprotein nitrogen in breast milk has focused on adult mothers. During recent years, teenage pregnancy has become a rising public health concern in many countries (Moran 2007), having significant social and reproductive consequences (Chedraui 2008). For Latin American countries such as Ecuador, adolescent pregnancies now account for almost one fifth of all pregnancies (UNFPA 2010). Because the vast majority of these women initiate breastfeeding (Ordóñez et al. 2005), the present study quantified concentrations of FAAs in milk collected at three stages of lactation and tested the hypotheses that the time-related changes in the patterning of FAA profiles would differ as a function of maternal age.

\footnotetext{
* Correspondence: mennella@monell.org

${ }^{2}$ Monell Chemical Senses Center, 3500 Market Street, Philadelphia, PA 19104-3308, USA

Full list of author information is available at the end of the article
}

\section{Materials and methods}

During 2009-2011, we recruited 65 non smoking women who gave birth at Hospital Gíneco-Obstétrico Isidro Ayora of Quito, a public obstetric hospital in Ecuador that serves low-income patients. Inclusion criteria included good health for dyad, singleton term birth without complications, and mother's intent to reside locally and exclusively breastfeed for at least 4 months. The study was approved by the Human Subjects Protection Committee at the Universidad San Francisco de Quito, and informed consent was obtained from each participant before participation. At study entry, all but 10 of the babies were weighed and all but 3 women were weighed and measured while wearing light clothing and without shoes.

Milk samples were collected after an overnight fast and during 06:00-08:00 hours at three time points: colostrum $(3.3 \pm 0.2$ days postpartum; range $=0-7)$, transition milk (15.1 \pm 0.1 days postpartum; range $=13-17)$, and mature milk ( 2 and/or 4 months postpartum). Colostrum was collected at the delivery hospital (26\%) or subjects' homes (74\%); transitional and mature milk samples were collected at subjects' homes.

Mothers used a breast pump to collect a minimum of $10 \mathrm{~mL}$ milk from each breast, which was pooled into a 50-mL Falcon aseptic tube. Samples were transported at $4^{\circ} \mathrm{C}$ to the laboratory within $2 \mathrm{~h}$, and proteins were immediately (within $2 \mathrm{~h}$ ) precipitated with 6\% 5-sulfosalicylic acid dihydrate and stored in liquid nitrogen until assayed for amino acids (Noguchi et al. 2006). Samples were sent to Japan in dry ice; each sample arrived frozen and was 
stored at $-70^{\circ} \mathrm{C}$ until analysis. The supernatant was purified with a $0.45-\mu \mathrm{m}$ filter; molecules $>10 \mathrm{kDa}$ were removed with an Amicon Ultra centrifugal filter (Millipore, Tokyo, Japan) and injected into an automatic amino acid analyzer (model L-8900; Hitachi, Tokyo, Japan) for cation-exchange chromatography separation. Each amino acid was detected by spectrophotometric analysis with ninhydrin reagent (Noguchi et al. 2006). The system has a high-reproducibility retention time with coefficient of variation (CV) $0.3 \%$ (arginine), peak area with CV 1.0\% (glycine, histamine), and limit of detection (LOD) of 3 pmol [signal-to-noise ratio $(\mathrm{S}: \mathrm{N})=2$; asparagine]. All samples were measured in duplicate; reproducibility was verified by measurements of standard preparations. Amino acid standards were intercalated with each sample to ensure reproducibility $\geq 98 \%$ or $\mathrm{CV}<2 \%$. LOD varied from $2-10 \mu \mathrm{mol} / \mathrm{L}$ and was specific to each amino acid. Values $<3$-fold the $\mathrm{S}: \mathrm{N}$ were considered to be in the LOD.

\section{Statistical analyses}

A mixed effects model including fixed effects for time point (stage of lactation: colostrum, transition, mature), maternal age (as a continuous variable), and random subject effect with a compound symmetry covariance structure were created to examine the relationship between stage of lactation, FAAs and maternal age. For each individual, the last observed value for that particular FAA (month 2 or 4) was used as value for mature milk. Least squares means (LSM: model-adjusted means) were calculated from mixed effects model with time point (stage of lactation) and other covariates as fixed effect and subject as the random effect. The differences in LSM between all time points were compared using a $t$-test. The models in this analysis were developed for each individual FAAs, as well as grouping of FAAs into Indispensible (Essential) or Dispensible (Non-Essential) or Total based on the classifications of the Dietary Reference Intakes for Women (Otten et al. 2006). Statistical significance was defined as $\mathrm{P}<0.05$. All data are reported as LSM ( \pm standard error).

\section{Results}

The 65 mothers were 14-27 years old (mean: $18.4 \pm 0.4$; $60 \% \leq 18$ ), with average body mass index of $24.6 \pm 0.4 \mathrm{~kg} / \mathrm{m}^{2}$ (normal weight, 58.1\%; overweight, 35.5\%; obese, 6.5\%). Twenty-eight of the 65 infants (43.1\%) were female. For the 55 babies with weight data, weight-for-age z-scores averaged $-0.29 \pm 0.17$ (range: -2.76 to 4.57 ; more than half (62\%) had z-scores $<0$.

We obtained a colostrum sample from each woman, transitional milk from 48 , and mature milk from 45 . There was no significant association between age and missing values for any time point. FAA levels changed significantly with increasing lactation (Table 1). Most FAAs (histidine, isoleucine, leucine, methionine, phenylalanine, threonine, valine, cysteine, tyrosine, alanine, aspartic acid, glutamic acid, glutamine, glycine, serine) increased as lactation progressed, four decreased (lysine, arginine, taurine, proline) and two were undetectable at any time point (tryptophan, asparagine). Glutamic acid, glutamine, taurine and alanine were most abundant in milk at each of the three stages of lactation. Both nonessential and essential FAAs increased as lactation progressed. Maternal age did not have a significant linear relationship with any of the FAAs (Table 1).

\section{Discussion}

The FAA profile in breast milk changed during the first four months of lactation: most FAAs increased as lactation progressed, whereas lysine, arginine, taurine and proline decreased with time. Tryptophan and asparagine were undetectable at all time points; most likely due to use of UV/VIS spectrometry in the detection of amino acid-ninhydrin derivatives. Maternal age did not have a significant linear relationship with any of the FAAs. Of all the FAAs, glutamic acid, glutamine, taurine and alanine were abundant with the two former FAA accounting for about $50 \%$ of total FAAs. These findings are relatively consistent with prior research in human (Rassin et al. 1978; Harzer et al. 1984; Agostoni et al. 2000a) and porcine (Wu et al. 2011) milk.

The abundance of FAAs in human milk seems to be a constant trait across age (Armstrong and Yates 1963; Ghadimi and Pecora 1963; Svanberg et al. 1977). However, in the present study many FAA levels were lower than previously reported (Agostoni et al. 2000b). We suggest two explanations, not mutually exclusive. First, although all mothers were primiparous, of normal or overweight status, delivered healthy term infants vaginally, and successfully breastfed for several months, many were Andean Mestizo women whose socio-economic status was low. Further, although common for adolescent births, many of the babies had weight-for-age z-scores $<0$ at study entry. Whether dietary habits and nutritional status of the mothers (Sanchez-Llaguno et al. 2013) may have been a contributing factor remains unknown.

Second, aspects of the experimental protocol may have resulted in lower FAA levels. In the present study milk samples were collected after an overnight fast. While the levels of free glutamate in the milk of lactating women collected after 8 h overnight fasting (Stegink et al. 1972) are comparable to the ones found in the present study, levels of FAA in milk appear to change throughout the day (Sánchez et al. 2013). Nevertheless, future studies should be conducted that compare levels of FAA in milk under experimentally controlled fasting and fed conditions. Because animal studies suggest that dietary branched-chain amino acids (BCAA) contribute to the synthesis of free and protein-bound glutamate, glutamine, aspartate and asparagine in milk (Li et al. 2009; Lei et al. 2012), the 
Table 1 Free amino acid content $(\mu \mathrm{mol} / \mathrm{dL})^{1}$ of human milk collected during three stages of lactation

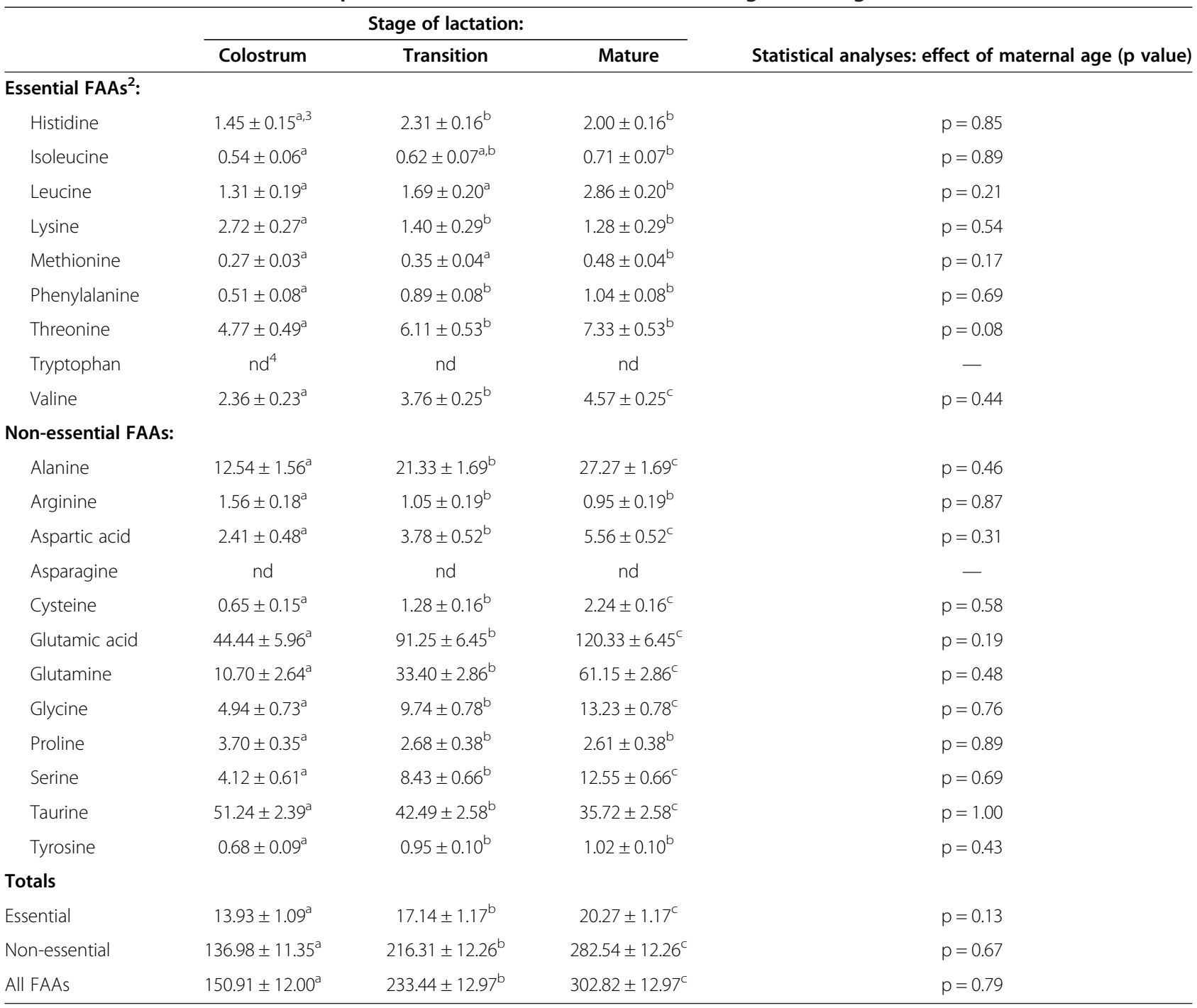

${ }^{1}$ Data are expressed as Least Squared Means $($ LSM $) \pm$ SEM. Estimates created from Mixed effects model.

${ }^{2}$ Classification of FAA based on Dietary Reference Intakes ${ }^{13}$.

${ }^{3}$ Different letters are statistically different from each other.

${ }^{4} \mathrm{nd}=$ not detectable; below the limit of detection.

short-term regulation of FAA content and the effects of dietary history in the short- and long- term in humans are important areas for future research.

The content of FAAs represents a small fraction (3-5\%) of total amino acids in human milk (Svanberg et al. 1977; Agostoni et al. 2000b). However, this is 100 times higher than the $0.05 \%$ FAA pool in tissues and even higher than the FAA pool in plasma (Christensen 1964). We found that the concentration of most FAAs is higher in mature milk than in colostrum or transitional milk. Because the total protein content of human milk decreases rapidly during the first month of lactation (Lonnerdal et al. 1976), as the baby grows, human milk contains more FAAs relative to total protein. What remains a mystery is the specific role that FAAs play in infant development and why the mammary tissue of humans and other mammals have develop a mechanism to deliver FAAs and specially glutamate and glutamine through milk? Because of its unbound nature, FAAs can be sensed by receptors in both the oral cavity (Chaudhari et al. 2000) and intestinal and gastric walls (San Gabriel and Uneyama 2013), likely conferring beneficial physiologic effects (e.g., gut development (Burrin et al. 2008) and satiety (Mennella et al. 2011; Ventura et al. 2012).

In summary FAA concentrations in human breast milk change over the first four months of lactation but are not related to mother's age. However, more research is needed to further explore the role of maternal age and nutritional status on the quality of her milk. Understanding the nature of these changes will help us develop better nutritional support for mothers and infants around the world. 


\section{Competing interests}

MEB, NF, MF, and JAM report no competing interest. ASG is an employee of Ajinomoto Co., Inc.

\section{Authors' contributions}

MEB designed the study, supervised study personnel, oversaw the execution of the study and data management, and assisted in writing the manuscript. JAM assisted in the design of the study, conducted the data analysis and wrote the manuscript. NF assisted in study design and execution, processed milk samples and entered the data. MF assisted in the design. ASG assisted in study design, oversaw the amino acid analysis of the milk samples and assisted in data analysis and the writing of the manuscript. All authors approved the final version of the manuscript.

\section{Acknowledgments}

This research was support by an investigator-initiated grant from the International Glutamate Technical Committee to MB. JAM was supported by U.S. National Institutes of Health R01 grant HD072301 from the Eunice Kennedy Shriver National Institute of Child Health and Human Development. The content is solely the responsibility of the authors and does not necessarily represent the official views of the National Institutes of Health. We gratefully acknowledge the supporting staff from the Hospital Gíneco-Obstétrico Isidro Ayora of Quito; Mariko Hirota for the amino acid analyses of the milk samples; Gustavo Molina, Esteffanía Villegas, and Daniela Villacís for assistance in data collection; and Kristi Roberts for data management. We thank Dr. Guoyao Wu for his critical review of the manuscript.

\section{Author details}

${ }^{1}$ Facultad de Ciencias de la Salud, Universidad de las Américas, Quito, Ecuador. ${ }^{2}$ Monell Chemical Senses Center, 3500 Market Street, Philadelphia, PA 19104-3308, USA. ${ }^{3}$ Colegio de Agricultura Alimentos y Nutrición, Universidad San Francisco de Quito, Quito, Ecuador. ${ }^{4}$ Ajinomoto Co., Inc., Tokyo, Japan.

Received: 3 February 2014 Accepted: 17 February 2014

Published: 21 February 2014

\section{References}

Agostoni C, Carratu B, Boniglia C et al (2000a) Free glutamine and glutamic acid increase in human milk through a three-month lactation period. J Pediatr Gastroenterol Nutr 31:508-512

Agostoni C, Carratu B, Boniglia C et al (2000b) Free amino acid content in standard infant formulas: comparison with human milk. J Am Coll Nutr 19:434-438

Armstrong MD, Yates KN (1963) Free amino acids in milk. Proc Soc Exp Biol Med 113:680-683

Burrin DG, Janeczko MJ, Stoll B (2008) Emerging aspects of dietary glutamate metabolism in the developing gut. Asia Pac J Clin Nutr 17:368-371

Chaudhari N, Landin AM, Roper SD (2000) A metabotropic glutamate receptor variant functions as a taste receptor. Nat Neurosci 3:113-119

Chedraui P (2008) Pregnancy among young adolescents: trends, risk factors and maternal-perinatal outcome. J Perinat Med 36:256-259

Christensen HN (1964) Free amino acids and peptides in tissues. In: Munro HN, Allison JB (eds) Mammalian protein metabolism, Vol 1. Academic Press, New York, pp 104-124

Ghadimi H, Pecora P (1963) Free amino acids of different kinds of milk. Am J Clin Nutr 13:75-81

Harzer G, Franzke V, Bindels JG (1984) Human milk nonprotein nitrogen components: changing patterns of free amino acids and urea in the course of early lactation. Am J Clin Nutr 40:303-309

Lei J, Feng D, Zhang Y et al (2012) Nutritional and regulatory role of branched-chain amino acids in lactation. Front Biosci 17:2725-2739

Li P, Knabe DA, Kim SW et al (2009) Lactating porcine mammary tissue catabolizes branched-chain amino acids for glutamine and aspartate synthesis. J Nutr 139:1502-1509

Lonnerdal B, Forsum E, Hambraeus L (1976) A longitudinal study of the protein, nitrogen, and lactose contents of human milk from Swedish well-nourished mothers. Am J Clin Nutr 29:1127-1133

Mennella JA, Ventura AK, Beauchamp GK (2011) Differential growth patterns among healthy infants fed protein hydrolysate or cow-milk formulas. Pediatrics 127:110-118
Moran VH (2007) Nutritional status in pregnant adolescents: a systematic review of biochemical markers. Matern Child Nutr 3:74-93

Noguchi Y, Zhang QW, Sugimoto T et al (2006) Network analysis of plasma and tissue amino acids and the generation of an amino index for potential diagnostic use. Am J Clin Nutr 83:513S-519S

Ordóñez J, Stupp PW, Monteith R et al (2005) Endemain 2004: Informe Final. Encuesta Demografía y de Salud Materna e Infantil: Informe Final [Demographic, Maternal and Infant Health Survey 2004: Final Report], Retrieved from http://www.cpc.unc.edu/pubs/2466

Otten JJ, Hellwig JP, Meyers LD (2006) Dietary Reference Intakes: The Essential Guide to Nutrient Requirements (No. 9780309157421). The National Academies Press, Washington DC

Rassin DK, Sturman JA, Guall GE (1978) Taurine and other free amino acids in milk of man and other mammals. Early Hum Dev 2:1-13

San Gabriel A, Uneyama H (2013) Amino acid sensing in the gastrointestinal tract. Amino Acids 45:451-461

Sánchez CL, Cubero J, Sánchez J et al (2013) Evolution of the circadian profile of human milk amino acids during breastfeeding. J Appl Biomed 11:59-70

Sanchez-Llaguno SN, Neira-Mosquera JA, Perez-Rodriguez F et al (2013) Preliminary nutritional assessment of the Ecuadorian diet based on a 24-h food recall survey in Ecuador. Nutr Hosp 28:1646-1656

Stegink LD, Filer LJ Jr, Baker GL (1972) Monosodium glutamate: effect of plasma and breast milk amino acid levels in lactating women. Proc Soc Exp Biol Med 140:836-841

Svanberg U, Gebre-Medhin M, Ljungqvist B et al (1977) Breast milk composition in Ethiopian and Swedish mothers. III. Amino acids and other nitrogenous substances. Am J Clin Nutr 30:499-507

United Nations Population Fund (UNFPA)-Ecuador (2010) Plan Nacional de Prevención del embarazo en adolescentes (National plan for the prevention of pregnancy in adolescents). http://www.unfpa.org/public/home/news/pid/ 6533, accessed 30 January 2014

Ventura AK, Beauchamp GK, Mennella JA (2012) Infant regulation of intake: the effect of free glutamate content in infant formulas. Am J Clin Nutr 95:875-881

Wu G, Bazer FW, Johnson GA et al (2011) Triennial growth symposium: important roles for L-glutamine in swine nutrition and production. J Anim Sci 89:2017-2030

doi:10.1186/2193-1801-3-104

Cite this article as: Baldeón et al:: Free amino acid content in breast milk of adolescent and adult mothers in Ecuador. SpringerPlus 2014 3:104.

\section{Submit your manuscript to a SpringerOpen ${ }^{\circ}$ journal and benefit from:}

- Convenient online submission

Rigorous peer review

- Immediate publication on acceptance

- Open access: articles freely available online

- High visibility within the field

- Retaining the copyright to your article

Submit your next manuscript at springeropen.com 